\title{
Life and work of Domenico Candeloro: an appreciation
}

\section{Carlo Bardaro $^{1}$ (D) Patrizia Pucci ${ }^{1}$ (D) $\cdot$ Anna Rita Sambucini ${ }^{1}$ (D) $\cdot$ Gianluca Vinti $^{1}$ (D)}

Received: 23 September 2020 / Accepted: 30 September 2020 / Published online: 29 October 2020

(c) The Author(s) 2020

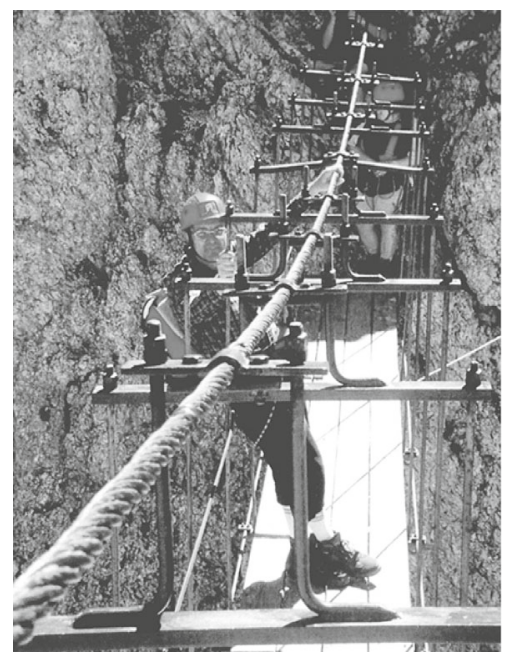

Professor Domenico Candeloro during one of his main passions: the mountains

(Via Ferrata Brigata Tridentina, Summer 1990, the Dolomites - Italy)

Domenico Candeloro passed away on May 3, 2019, in Rome. He was Full Professor of Mathematical Analysis at University of Perugia.

In memory of a Master, a Fair Man, a Friend.

$凶 \quad$ Anna Rita Sambucini

anna.sambucini@unipg.it

Carlo Bardaro

carlo.bardaro@unipg.it

Patrizia Pucci

patrizia.pucci@unipg.it

Gianluca Vinti

gianluca.vinti@unipg.it

1 Department of Mathematics and Computer Sciences, University of Perugia, 1, Via Vanvitelli, 06123 Perugia, Italy 


\section{A personal memoir}

Domenico Candeloro was born in Udine on October 18th, 1951 and died suddenly in Rome on May 3rd, 2019. He graduated in Perugia in 1974 under the direction of his Master, Professor Calogero Vinti, and worked with many Italian and foreign scholars. He was visiting professor at the universities of Florida-Gainesville, Reading (U.K.) and Bratislava (Slovakia).

He became Associate Professor in 1983 and then Full Professor in Analysis in 1993. He was called, as Full Professor, by the University of Palermo in the academic year 1994-1995 and then he was called by the University of Perugia where he remained until his death. He was one of the key professors of the Degree Course in Mathematics and of the Engeenering Faculty of the University of Perugia, and he has carried out teaching and research activities, as a teacher of advanced courses, continuously since 1975.

Candeloro was a highly talented mathematician, with a lively, very acute and profound intelligence. He worked in Functional Analysis, Measure and Integration Theories, with particular attention in applications to the Calculus of Variations, Approximation Theory, Stochastic and Multivalued Integration. In particular he dealth with Finitely Additive Measures, especially with their structural problems and their applications to Probability.

He published 86 research papers; the second-last article [86], is published in this volume "Measure, Integration and Applications" of the B.U.M.I. that the Italian Mathematical Union wanted to dedicate to him in memory. His scientific contributions are, on the other hand, much greater, since he very often gave suggestions, followed or collaborated with other researchers. In May 2015 he received the Ames Award, sponsored by the American Mathematical Society, for the best publication of the year 2014 in the Journal of Mathematical Analysis and Applications.

Some of his results can be summarized as follows: his first papers are concerned with problems from the Calculus of Variations and Optimal Control, obtaining fundamental results on the theory of Burkill-Cesari and Weierstrass integrals, a topic inherited from the work of his Master, Professor Calogero Vinti [1-3,5,11,13] and on the theory of Serrin's integral $[6,12]$.

Then, he developed his research in the direction of Measure Theory and Integration Processes. In the field of Measure Theory, finitely additive measures played an important role in his research, especially for what concerns non atomicity, decompositions, extensions and restrictions. Results on these subjects are contained for example in [8-10,17,26,33]. In [14-17], using sliding hump techniques, some Brooks-Jewett, Vitali-Hahn-Saks, Nikodým convergence, Nikodým boundedness and Lebesgue decomposition theorems are proved, for finitely or countably additive set functions, with values in topological groups while, in the setting of lattice group, in [44] some Stone and Carathéodory-type extension results and Drewnowski-type theorems are proved for finitely additive measures. These properties are used to prove some Lebesgue decomposition theorems for lattice group-valued measures, both in the finitely additive and in the countably additive case. In [61,62] some BrooksJewett, Vitali-Hahn-Saks, Nikodým convergence and Dieudonné-type theorems are proved for finitely additive measures taking values in lattice groups, in which the pointwise convergence of the involved measures is intended as in the classical sense, and not necessarily with respect to a single regulator. The used tools are sliding hump techniques and the MaedaOgasawara-Vulikh representation theorem of Archimedean vector lattices.

It is worth to mention his investigation about Radon Nikodym's type representations both in countably additive and finitely additive cases. In [24,42,77], Candeloro linked the existence of the derivative to the geometric shape of the range of the pair of the involved measures in 
the non countably additive cases, while in the countably additive case examples are given together with some conditions, ensuring the existence in semifinite, strictly localizable and Maharam measures, since in general the Radon Nikodym's Theorem fails for unbounded measures.

For what concerns the Integration, Candeloro has addressed the problem of the comparison of different generalizations of Lebesgue integral, that is one of the milestones of the modern theory of integration. In the seminal paper [32], an integral for interval functions taking values in a vector lattice is studied. By means of this tool, the Riemann-Stieltjes integral and some kinds of stochastic integrals, like Itô and Stratonovich, are deduced. In [46,47,52] some Kondurar'-type theorems for the Riemann-Stieltjes integral are proved in the context of vector lattices. Moreover, a version of the Itô formula is obtained for two-variable functions in the vector lattice setting, and some applications to stochastic differential equations are given. This line of research has also led to the papers [65,73], the first of which was awarded by the 2014 Ames Prize quoted before. In this paper the Vitali convergence theorem is extended, concerning with sequences in $L^{p}$ and weak compactness. Having in mind a wide spectrum of applications, the notions of a norm and a normed linear space are replaced by those of a modular and a modular space. Working in the general setting of vector lattice-valued modulars with respect to filter convergence, general versions of the Vitali and the Lebesgue dominated convergence theorems are proved. Several interesting applications are given, in particular to modular convergence of moment operators in the vector lattice setting, and to convergence of the Itô integral with respect to Brownian motion.

Finally, over the last five years, in the multivalued case, he has examined relationship among "gauge integrals" (Henstock, Mc Shane, Birkhoff) and "functional integrals" (Dunford, Pettis, Henstock-Kurweil-Pettis) of multifunctions whose values are weakly compact and convex subsets of a general Banach space, not necessarily separable. Within this field of research, are also positioned studies on the decomposition property for integrable multifunctions, i.e., when an integrable "in a certain sense" multifunction can be represented as a sum of one of its integrable selections and a multifunction integrable in a narrower sense. The decomposition theorems are important tools of the theory of multivalued integration since they allow to see an integrable multifunction as a translation of a multifunction with better properties. Valuable results in this area are contained in the following papers $[67,72,78,81]$; in particular the existence of variational-Henstock selections solved a problem that had remained unsolved in the last 10 years. He also applied these results to stochastic processes in vector spaces $[36,51,76,83]$.

Candeloro was not only interested in pure mathematics but also loved to deal with real applications to engineering [74,75] or to Mathematical Economy [82]: in the non additive case, using the Choquet integral, he studied the search of equilibria for a model where the space of agents is decomposed into a large number of sections, each of which is an authonomous economic model, but coalitions can be created also among members of different sections, according with some rules.

He has also been involved in the dissemination of mathematics, in collaboration with Mathesis; we only want to remember here his lecture "Io speriamo che me la ricavo" held in the "Fridays of Science" organized by the Faculty of Sciences of the University of Perugia in 2007.

We do not want to just talk about his scientific contributions, but also to mention his human qualities and his relationships with the people he was close to. Mimmo is the mildest and most generous person we have ever known, with two great passions besides his family: that of to climb peaks and Mathematics. Both fully reflects his personality. To climb mountains or to solve a mathematical problem, were not only pure physical or intellectual exercises for 
him, but also an intense moment of spirituality, in which he felt part of the immensity and mystery of creation.

He also loved poetry, cultivated in a more reserved way, even if he were "the official poet of our Department": we gave him this unofficial recognition because he used to write a rhyming poem for every celebration of those who made a career upgrade or who retired.

The disappearance of Professor Domenico Candeloro represents a great loss for the Italian mathematical community and for all the students, colleagues, and the staff of both the Department of Mathematics and Computer Science and the "Polo Didattico e Scientifico di Terni", who had the great fortune to meet him and to know his extraordinary human and scientific qualities. His figure, his humanity and his scientific qualities have been remembered at the University of Perugia in two events:

- on October 30, 2019, the Department of Mathematics and Computer Science named the Meeting Room after him uncovering a plaque with the sentence: "Professor Domenico Candeloro, Ricercatore profondo, Esempio di umiltà, umanità e saggezza. Ha trasmesso $i$ valori della Matematica permeando di poesia il nostro Dipartimento" (Professor Domenico Candeloro, Deep Researcher, Example of humility, humanity and wisdom. He transmitted the values of Mathematics permeating our department with poetry);

- on January 20, 2020, the "Polo Didattico e Scientifico di Terni" discovered a plaque in his memory in the lobby of the Pole "Al Prof. Mimmo Candeloro che con la sua grande umanità ha saputo trasmettere l'amore per la Matematica e $i$ valori profondi della vita. Il suo ricordo sarà sempre con noi" (To Prof. Mimmo Candeloro who with his great humanity has been able to transmit the love for Mathematics and the deep values of the life. His memory will always be with us).

He leaves a great mathematical and human heritage among the colleagues, among his many scientific collaborators who have benefited from his great mathematical and human skills, and a great precious example for all of us to imitate. Grace Lichtenstein wrote: A wise man once said: works for a cause, not for applause. Live your life to express, not to impress. Don't strive to make your presence noticed, just make your absence felt. No other sentences could, in so few words, collect the essence of his life.

\section{Carlo Bardaro \\ Patrizia Pucci \\ Anna Rita Sambucini \\ Gianluca Vinti}

Funding Open access funding provided by Università degli Studi di Perugia within the CRUI-CARE Agreement.

\section{Compliance with ethical standards}

Conflict of interest On behalf of all authors, the corresponding author states that there is no conflict of interest.

Open Access This article is licensed under a Creative Commons Attribution 4.0 International License, which permits use, sharing, adaptation, distribution and reproduction in any medium or format, as long as you give appropriate credit to the original author(s) and the source, provide a link to the Creative Commons licence, and indicate if changes were made. The images or other third party material in this article are included in the article's Creative Commons licence, unless indicated otherwise in a credit line to the material. If material is not included in the article's Creative Commons licence and your intended use is not permitted by statutory regulation or exceeds the permitted use, you will need to obtain permission directly from the copyright holder. To view a copy of this licence, visit http://creativecommons.org/licenses/by/4.0/. 


\section{References}

1. Candeloro, D.: L'area di Geöcze, per prodotti di applicazioni, come integrale alla Burkill-Cesari, (Italian) Istit. Lombardo Accad. Sci. Lett. Rend. A 110(2), 493-513 (1976)

2. Candeloro, D.: The Burkill-Cesari integral and its relation to absolute continuity, (Italian). Rend. Circ. Mat. Palermo 26(1-3), 251-274 (1977)

3. Candeloro, D., Pucci, P.: Some considerations regarding the Riemann-Stieltjes integral and the Weierstrass integral (Italian). Atti Accad. Naz. Lincei Rend. Cl. Sci. Fis. Mat. Natur., 63(3-4), 187-191 (1977)

4. Candeloro, D., Pucci, P.: Some bounds for the Riemann-Stieltjes integral and the Weierstrass integral (Italian). Atti Sem. Mat. Fis. Univ. Modena 26(2), 256-279 (1977)

5. Candeloro, D., Pucci, P.: A lower closure theorem with respect to a sequence of measures for optimal control problems (Italian). Atti Sem. Mat. Fis. Univ. Modena 26(2), 280-292 (1977)

6. Bardaro, C., Candeloro, D.: The approximation of the Burkill-Cesari integral for sublinear functionals on measures, and applications to the multiple integral of the calculus of variations (Italian). Atti Sem. Mat. Fis. Univ. Modena 26(2), 339-362 (1977)

7. Candeloro, D., Pucci, P.: A criterion for weak compactness in the sense of Dunford and Pettis (Italian). Atti Accad. Naz. Lincei Rend. Cl. Sci. Fis. Mat. Nat. 64(2), 124-129 (1978)

8. Candeloro, D., Sacchetti Martellotti, A.: Some problems concerning subadditive scalar measures and applications to the case of finite additivity (Italian). Atti Sem. Mat. Fis. Univ. Modena 27(2), 284-296 (1978)

9. Candeloro, D., Martellotti Sacchetti, A.: On the range of a vector measure (Italian). Atti Sem. Mat. Fis. Univ. Modena 28(1), 102-111 (1979)

10. Candeloro, D., Martellotti, A.: Continuous finitely additive measures which are extensions of nonatomic measures. Atti Sem. Mat. Fis. Univ. Modena 29(2), 328-344 (1980)

11. Candeloro, D., Pucci, P.: The Burkill-Cesari integral over a rectangle and applications to the FubiniTonelli integral with respect to pairs of continuous curves (Italian). Boll. Un. Mat. Ital. B (5) 17(3), 835-859 (1980)

12. Bardaro, C., Candeloro, D.: Approximation theorems for the multiple integral of the calculus of variations (Italian). Rend. Circ. Mat. Palermo 30(1), 63-82 (1981)

13. Candeloro, D., Pucci, P.: The Burkill-Cesari integral as integral of the calculus of variations (Italian). Boll. Un. Mat. Ital. B (5) 18(1), 1-24 (1981)

14. Candeloro, D.: Uniform exhaustivity and absolute continuity (Italian). Boll. Un. Mat. Ital. B (6) 4(3), 709-724 (1985)

15. Candeloro, D.: The Vitali-Hahn-Saks, Dieudonné and Nikodým theorems (Italian). In: Proceedings of the Conference Commemorating the 1st Centennial of the Circolo Matematico di Palermo (Italian) (Palermo, 1984), Rend. Circ. Mat. Palermo (2) Suppl. No. 8, pp. 439-445 (1985)

16. Candeloro, D.: Some theorems on uniform boundedness (Italian). Rend. Accad. Naz. Sci. XL Mem. Mat. 9(1), 249-260 (1985)

17. Candeloro, D., Letta, G.: On the Vitali-Hahn-Saks and Dieudonné theorems (Italian). Rend. Accad. Naz. Sci. XL Mem. Mat. 9(1), 203-213 (1985)

18. Candeloro, D.: Transformation-invariant measures in higher dimensions (Italian). Atti Sem. Mat. Fis. Univ. Modena 35(1), 33-42 (1987)

19. Candeloro, D., Martellotti, A.: An overview of some recent results concerning finitely additive measures (Italian). Atti Sem. Mat. Fis. Univ. Modena 35(2), 327-334 (1987)

20. Candeloro, D., Pucci, S.: Radon-Nikodým derivatives and conditioning in fuzzy measure theory. Stochastica 11(2-3), 107-120 (1987)

21. Boccuto, A., Candeloro, D.: On the existence of continuous invariant means with respect to amenable semigroups. Rend. Mat. Appl. 10(2), 303-319 (1990)

22. Boccuto, A., Candeloro, D.: A sandwich-type theorem for invariant measures. Atti Sem. Mat. Fis. Univ. Modena 38(2), 415-424 (1990)

23. Boccuto, A., Candeloro, D.: Sandwich theorems and applications to invariant measures. Atti Sem. Mat. Fis. Univ. Modena 38(2), 511-524 (1990)

24. Candeloro, D., Martellotti, A.: Geometric properties of the range of two-dimensional quasi-measures with respect to the Radon-Nikodým property. Adv. Math. 93(1), 9-24 (1992)

25. Candeloro, D.; Martellotti, A., Radon-Nikodým theorems for vector-valued finitely additive measures. Rend. Mat. Appl. 12(4), 1071-1086 (1993) (1992)

26. Bhaskara Rao, K.P.S., Candeloro, D., Martellotti, A.: $\mathbb{R}^{n}$-valued finitely additive measures admitting countably additive restrictions preserving the range. J. Math. Anal. Appl. 177(1), 166-169 (1993)

27. Boccuto, A., Candeloro, D.: Invariant means with special properties. Atti Sem. Mat. Fis. Univ. Modena 41(1), 167-180 (1993) 
28. Boccuto, A., Candeloro, D.: Extensions and uniqueness theorems for invariant measures. Atti Sem. Mat. Fis. Univ. Modena 41(1), 181-194 (1993)

29. Boccuto, A., Candeloro, D.: Sandwich theorems, extension principles and amenability. Atti Sem. Mat. Fis. Univ. Modena 42(1), 257-271 (1994)

30. Candeloro, D.: Multidimensional variations and countably additive restrictions. Atti Sem. Mat. Fis. Univ. Modena 43(1), 245-251 (1995)

31. Candeloro, D., Martellotti, A.: Stochastic processes and applications to countably additive restrictions of group-valued finitely additive measures. Collect. Math. 47(1), 23-33 (1996)

32. Candeloro, D.: Riemann-Stieltjes integration in Riesz spaces. Rend. Mat. Appl. (7) 16(4), 563-585 (1996)

33. Brooks, J.K., Candeloro, D., Martellotti, A.: On finitely additive measures in nuclear spaces. Atti Sem. Mat. Fis. Univ. Modena 46(1), 37-50 (1998)

34. Bardaro, C., Candeloro, D., Pucci, P.: Proceedings of the International Congress Conferenze in Onore di Calogero Vinti. Atti Sem. Mat. Fis. Univ. Modena, Supplemento al, vol. 46, pp. 989+xxxiv (1998)

35. Candeloro, D.: Some remarks on the first digit problem, Dedicated to Prof. C. Vinti (Italian) (Perugia, 1996). Atti Sem. Mat. Fis. Univ. Modena 46(suppl.), 511-532 (1998)

36. Brooks, J.K., Candeloro, D.: Weak stochastic integration in Banach spaces. Atti Sem. Mat. Fis. Univ. Modena 49(2), 513-522 (2001)

37. Boccuto, A., Candeloro, D.: Dieudonné-type theorems for set functions with values in (l)-groups. Real Anal. Exchange 27(2), 473-483 (2001/02)

38. Boccuto, A., Candeloro, D.: Uniform $s$-boundedness and convergence results for measures with values in complete $l$-groups. J. Math. Anal. Appl. 265(1), 170-194 (2002)

39. Boccuto, A., Candeloro, D.: Vitali and Schur-type theorems for Riesz-space-valued set functions. Atti Sem. Mat. Fis. Univ. Modena 50(1), 85-103 (2002)

40. Candeloro, D.: Convergence theorems for measures with values in Riesz spaces, Uncertainty modelling, 2001 (Bratislava). Kybernetika 38(3), 287-295 (2002)

41. Brooks, J.K., Candeloro, D.: Integration with respect to functions of unbounded variation. In: Functional analysis, VII (Dubrovnik, 2001), Various Publ. Ser. (Aarhus), vol. 46, pp. 63-81. Univ. Aarhus, Aarhus (2002)

42. Candeloro, D.: Volčič, A., Radon-Nikodým theorems. Handbook of measure theory, vols. I, II, pp. 249294. North-Holland, Amsterdam (2002)

43. Brooks, J.K., Candeloro, D.: On the Caccioppoli integral. Atti Sem. Mat. Fis. Univ. Modena 51(2), 415-431 (2003)

44. Boccuto, A., Candeloro, D.: Convergence and decompositions for $l$-group-valued set functions. Comment. Math. (Prace Mat.) 44(1), 11-37 (2004)

45. Boccuto, A., Candeloro, D.: Uniform boundedness theorems in Riesz spaces. Atti Sem. Mat. Fis. Univ. Modena Reggio Emilia 52(2), 369-382 (2004)

46. Boccuto, A., Candeloro, D.: Ito Formula in Riesz spaces. In: Proceedings of the Tenth Int. Conference IPMU, Perugia, July 2004, pp. 1807-1814 (2004)

47. Boccuto, A., Candeloro, D.: Kondurar Theorem in Riesz spaces. In: Proceedings of the Tenth Int. Conference IPMU, Perugia, July 2004, pp. 1815-1822 (2004)

48. Brooks, J.K., Candeloro, D.: The Rickart integral and Yosida-Hewitt decompositions. Tatra Mt. Math. Publ. 28(part II), 227-240 (2004)

49. Boccuto, A., Candeloro, D.: Several types of equations in Riesz spaces and applications. Acta Math. 8, 7-20 (2005). (Faculty of Natural Sciences Constantine, The Philosopher University Nitra)

50. Boccuto, A., Candeloro, D.: A survey of decomposition and convergence theorems for $l$-group-valued measures. Atti Sem. Mat. Fis. Univ. Modena Reggio Emilia 53(2), 243-260 (2005)

51. Brooks, J.K., Candeloro, D., Martellotti, A.: Stochastic processes in nuclear spaces: quasi-martingales and decompositions. Math. Slovaca 55(3), 271-282 (2005)

52. Boccuto, A., Candeloro, D., Kubińska, E.: Kondurar theorem and Itô formula in Riesz spaces. J. Concr. Appl. Math. 4(1), 67-90 (2006)

53. Brooks, J.K., Candeloro, D.: On the space of functions integrable with respect to functions of unbounded variation. Atti Sem. Mat. Fis. Univ. Modena Reggio Emilia 54(1-2), 115-123 (2006)

54. Boccuto, A., Candeloro, D., Sambucini, A.R.: Stieltjes-type integrals for metric semigroup-valued functions defined on unbounded intervals. PanAm. Math. J. 17(4), 39-58 (2007)

55. Boccuto, A., Candeloro, D.: The contraction principle in Riesz spaces and applications to differential and stochastic equations. Atti Sem. Mat. Fis. Univ. Modena Reggio Emilia 55(1-2), 13-31 (2008) (2007)

56. Boccuto, A., Candeloro, D.: Integral and differential calculus in Riesz spaces and applications. J. Appl. Funct. Anal. 3(1), 89-111 (2008)

57. Boccuto, A., Candeloro, D.: Sobczyk-Hammer decompositions and convergence theorems for measures with values in $l$-groups. Real Anal. Exchange 33(1), 91-105 (2008) 
58. Boccuto, A., Candeloro, D., Riečan, B.: Abstract generalized Kurzweil-Henstock-type integrals for Riesz space-valued functions. Real Anal. Exchange 34(1), 171-194 (2009)

59. Boccuto, A., Candeloro, D.: Integral and ideals in Riesz spaces. Inform. Sci. 179(17), 2891-2902 (2009)

60. Boccuto, A., Candeloro, D.: Defining limits by means of integrals, vector measures, integration and related topics. In: Oper. Theory Adv. Appl., vol. 201, pp. 79-87. Birkhäuser Verlag, Basel (2010)

61. Boccuto, A., Candeloro, D.: Some new results about Brooks-Jewett and Dieudonné-type theorems in (l)-groups. Kybernetika 46(6), 1049-1060 (2010)

62. Boccuto, A., Candeloro, D.: Uniform $(s)$-boundedness and regularity for $(l)$-group-valued measures. Cent. Eur. J. Math. 9(2), 433-440 (2011)

63. Boccuto, A., Candeloro, D.: Differential calculus in Riesz spaces and applications to $g$-calculus. Mediterr. J. Math. 8(3), 315-329 (2011)

64. Boccuto, A., Candeloro, D., Sambucini, A.R.: A Fubini theorem in Riesz spaces for the KurzweilHenstock integral. J. Funct. Spaces Appl. 9(3), 283-304 (2011)

65. Boccuto, A., Candeloro, D., Sambucini, A.R.: Vitali-type theorems for filter convergence related to vector lattice-valued modulars and applications to stochastic processes. J. Math. Anal. Appl. 419(2), 818-838 (2014). Winner of the 2014 JMAA Ames Awards. https://www.journals.elsevier.com/journalof-mathematical-analysis-and-applications/news/winners-of-the-2014-jmaa-ames-awards-announced

66. Candeloro, D., Sambucini, A.R.: Order-type Henstock and Mc Shane integrals in Banach lattices setting. Subotica 2014, 55-59 (2014). https://doi.org/10.1109/SISY.2014.6923557

67. Boccuto, A., Candeloro, D., Sambucini, A.R.: Henstock multivalued integrability in Banach lattices with respect to pointwise non atomic measures. Atti Accad. Naz. Lincei Rend. Lincei Mat. Appl. 26(4), 363383 (2015)

68. Candeloro, D., Sambucini, A.R.: Filter convergence and decompositions for vector lattice-valued measures. Mediterr. J. Math. 12(3), 621-637 (2015)

69. Candeloro, D., Sambucini, A.R.: Comparison between some norm and order gauge integrals in Banach lattices. PanAm. Math. J. 25(3), 1-16 (2015)

70. Candeloro, D., Croitoru, A., Gavriluţ, A., Sambucini, A.R.: An extension of the Birkhoff integrability for multifunctions. Mediterr. J. Math. 13(5), 2551-2575 (2016)

71. Candeloro, D., Croitoru, A., Gavriluţ, A., Sambucini, A.R.: Atomicity related to non-additive integrability. Rend. Circ. Mat. Palermo Ser. 2 65(3), 435-449 (2016)

72. Candeloro, D., Di Piazza, L., Musiał, K., Sambucini, A.R.: Gauge integrals and selections of weakly compact valued multifunctions. J. Math. Anal. Appl. 441(1), 293-308 (2016)

73. Boccuto, A., Candeloro, D., Sambucini, A.R.: $L^{p}$ spaces in vector lattices and applications. Math. Slovaca 67(6), 1409-1426 (2017)

74. Candeloro, D., Cardelli, E., Faba, A., Pompei, M., Quondam Antonio, S.: In-plane magnetic anisotropy detection of crystal grain orientation in goss-textured ferromagnets. IEEE Trans. Magn. 53(11), art. n. 7944683 (2017)

75. Candeloro, D., Cardelli, E., Faba, A., Pompei, M., Quondam Antonio, S.: In-plane magnetic anisotropy detection for crystal grain orientation in Goss-textured ferromagnets. In: IEEE International Magnetics Conference, INTERMAG 2017, art. n. 8007944 (2017)

76. Candeloro, D., Sambucini, A.R.: A Girsanov result through Birkhoff integral, Computational science and its applications-ICCSA 2018. Part I, Lecture Notes in Comput. Sci., vol. 10960, pp. 676-683. Springer, Cham (2018). https://doi.org/10.1007/978-3-319-95162-1_47

77. Candeloro, D., Croitoru, A., Gavriluţ, A., Sambucini, A.R.: A multivalued version of the Radon-Nikodým theorem, via the single-valued Gould integral. Austral. J. Math. Anal. Appl. 15(2), Art. 9, 16 (2018)

78. Candeloro, D., Di Piazza, L., Musiał, K., Sambucini, A.R.: Relations among gauge and Pettis integrals for $\operatorname{cwk}(X)$-valued multifunctions. Ann. Mat. Pura Appl. 197(1), 171-183 (2018)

79. Candeloro, D., Labuschagne, C.C.A., Marraffa, V., Sambucini, A.R.: Set-valued Brownian motion. Ric. Mat. 67(2), 347-360 (2018)

80. Candeloro, D., Di Piazza, L., Musiał, K., Sambucini, A.R.: Some new results on integration for multifunction. Ric. Mat. 67(2), 361-372 (2018)

81. Candeloro, D., Di Piazza, L., Musiał, K., Sambucini, A.R.: Multifunctions determined by integrable functions. Int. J. Approx. Reason. 112, 140-148 (2019)

82. Candeloro, D., Mesiar, R., Sambucini, A.R.: A special class of fuzzy measures: Choquet integral and applications. Fuzzy Sets Syst. 355, 83-99 (2019)

83. Candeloro, D., Sambucini, A.R., Trastulli, L.: A vector Girsanov result and its applications to conditional measures via the Birkhoff integrability. Mediterr. J. Math. 16, 144 (2019). https://doi.org/10.1007/s00009019-1431-x 
84. Candeloro, D., Croitoru, A., Gavriluţ, A., Iosif, A., Sambucini, A.R.: Properties of the Riemann-Lebesgue integrability in the non-additive case. Rend. Circ. Mat. Palermo 69(2), 577-589 (2020). https://doi.org/ 10.1007/s12215-019-00419-y

85. Candeloro, D., Di Piazza, L., Musiał, K., Sambucini, A.R.: Integration of multifunctions with closed convex values in arbitrary banach spaces. J. Convex Anal. 27(4) (2020)

86. Candeloro, D., Di Piazza, L., Musiał, K., Sambucini, A.R.: Multi-integrals of finite variation. Bull. Un. Mat. Ital. 13(4) (2020). https://doi.org/10.1007/s40574-020-00217-w

87. Candeloro, D.; Sambucini, A. R.; Trastulli, L.: A Girsanov result for the Pettis integral. Real Anal. Exchange 46(1) (2021). https://doi.org/10.14321/realanalexch.46.1.0001

Publisher's Note Springer Nature remains neutral with regard to jurisdictional claims in published maps and institutional affiliations. 